\title{
Penerapan Data Mining Terhadap Minat Siswa Dalam Mata Pelajaran Matematika Dengan Metode K-Means
}

\author{
Sufajar Butsianto, S.Kom, M.Kom ${ }^{1}$, Nurhali Saepudin. S.Kom ${ }^{2}$ \\ Universitas Pelita Bangsa, Jl. Inspeksi Kalimalang No.9, Cibatu, Kec. Cikarang Pusat, \\ Bekasi, Jawa Barat 17530 \\ ${ }^{1}$ sufajar@pelitabangsa.ac.id
}

\begin{abstract}
Kumpulan data nilai siswa pada sebuah sekolah dapat diolah dengan memanfaatkan teknologi data mining untuk menghasilkan pengetahuan menarik dan bermanfaat, yang selama ini tidak diketahui secara manual. Salah satu teknik data mining adalah clustering. Algoritma K-Means dapat digunakan untuk mengelompokan minat siswa terhadap mata pelajaran matematika pada sebuah sekolah sehingga dapat bermanfaat bagi pengguna kebijakan dalam proses pengambilan keputusan. Proses ini menghasilkan 2 cluster yaitu ( minat ) Matematika dan ( kurang minat ) matematika, dengan menggunakan teknik data mining menggunakan algoritma K-Means, dan akurasi diukur dengan Davies Bouldin Index. Pengujian menggunakan validasi DBI (Davies Bouldin Index) diperoleh nilai untuk tiap-tiap cluster. Untuk kelas 10 pengujian cluster 1 menghasilkan nilai DBI 0.941 dan cluster 2 nilai DBI 0.335 , kelas 11 pengujian cluster 1 menghasilkan nilai DBI 0.660 dan cluster 2 nilai DBI 0.506, kelas 12 pengujian cluster 1 menghasilkan nilai DBI 0.271 dan cluster 2 nilai DBI 0.111. Dari perhitungan Davies Bouldin Index (DBI) dapat disimpulkan bahwa jika semakin kecil nilai Davies Bouldin Index (DBI) yang diperoleh (non negatif $>=0$ ) maka cluster tersebut semakin baik.
\end{abstract}

Kata kunci : Data Mining, Clustering,K-Means, Matematika

\section{Pendahuluan}

Kemampuan matematika yang diperlukan untuk menguasai dan menciptakan teknologi di masa depan, menjadikan matematika yang kuat perlu dibina sejak dini. Masyarakat beranggapan bahwa matematika menjadi tolak ukur kecerdasan dan kepandaian anak dalam belajar. Namun demikian matematika masih dipandang sebagai salah satu bidang studi yang tidak disenangi atau bahkan bias jadi paling dibenci dan masih melekat kebanyakan siswa yang mempelajarinya sampai saat ini. Hal itulah yang mempengaruhi minat seorang siswa dengan matematika, berbeda dengan siswa lainnya. Minat belajar cenderung menghasilkan prestasi tinggi, sebaliknya minat belajar yang kurang akan menghasilkan prestasi yang rendah. Hal itulah yang menyebabkan minat setiap siswa berbeda dengan siswa lainnya.

Dalam penelitian ini penulis melakukan penelitian tentang minat siswa terhadap Mata Pelajaran Matematika menggunakan algoritma K-means di SMK Binamitra Cikarang Timur, dimana penelitian ini bertujuan untuk mengetahui hasil dari pengklasifikasikan atau pengelompokan minat siswa terhadap mata pelajaran matematika berdasarkan nilai siswa. Objek penelitian yang penulis teliti berasal dari 334 data siswa kelas 10,11, dan 12 dari semua jurusan di SMK Binamitra. Penelitian yang digunakan penulis yaitu penelitian kualitatif, karena data yang diperoleh nantinya adalah berupa kata-kata. Kata-kata tersebut diperoleh dari proses filter data yang telah berhasil dibersihkan. Dimana kata-kata tersebut nantinya akan diproses untuk mengetahui hasil clustering dan akurasi didalamnya.

Pemilihan metode K-Means dikarenakan metode ini harus menggunakan data fisik tidak abstrak dan bersifat jelas, hal ini sesuai dengan data yang akan digunakan pada permasalahan di dalam pengelompokan bimbingan belajar di SMK Binamitra. Selain itu, metode ini bersifat fleksibel sebab pengguna dapat menentukan jumlah cluster yang akan dibuat. Dalam metode clustering mempartisi data ke dalam kelompok, sehingga data yang memiliki karakteristik yang sama dikelompokkan ke dalam satu cluster yang sama. Jumlah kelompok yang dapat diidentifikasi tergantung pada banyak dan variasi data obyek. Tujuan dari pengelompokan sekumpulan data obyek kedalam beberapa kelompok yang mempunyai karakteristik tertentu dan dapat dibedakan satu sama lainnya adalah untuk analis dan interprestasi lebih lanjut sesuai dengan tujuan penelitian yang dilakukan[3].

\section{Tinjauan Pustaka}

\subsection{Sistem K-means}

Data mining berkembang menjadi alat bantu untuk mencari pola-pola yang berharga dalam suatu basisdata yang sangat besar jumlahnya, sehingga tidak memungkinkan dicari secara manual. Beberapa teknik data mining dapat diklasifikasikan ke dalam kategori berikut, meliputi klasifikasi, clustering, penggalian kaidah asosiasi, analisa pola sekuensial, prediksi, visualisasi data dan lain sebagainya. Teknik 
clustering adalah teknik yang digunakan untuk menangani data yang besar dengan banyak atribut ke dalam sejumlah kelompok kecil. Clustering dilakukan dengan terlebih dahulu menganalisis bagian kecil dari data untuk menentukan klaster. Clustering merupakan pengelompokkan record, observasi, atau kasus ke dalam kelas-kelas objek yang mirip. Clustering berbeda dengan klasifikasi dimana dalam clustering tidak terdapat variabel target. Salah satu algoritma clustering adalah K-Means. Clustering merupakan suatu teknik data mining yang membagi-bagikan data ke dalam beberapa kelompok (grup atau cluster atau segmen) yang tiap cluster dapat ditempati beberapa anggota bersama-sama. Setiap obyek dilewatan ke grup yang paling mirip dengannya. Ini menyerupai menyusunan binatang dan tumbuhan ke dalam keluarga - keluarga yang para anggotanya mempunyai kemiripan. Clustering tidak mensyaratkan pengetahuan sebelumnya dari grup yang dibentuk, juga dari para anggota yang harus mengikutinya[2].

Algoritma K-Means diperkenalkan oleh J.B. MacQueen pada tahun 1976, salah satu algoritma clustering sangat umum yang mengelompokkan data sesuai dengan karakteristik atau ciri-ciri bersama yang serupa. Grup data ini dinamakan sebagai cluster. Data di dalam suatu cluster mempunyai ciri-ciri (atau fitur, karakteristik, atribut, properti) serupa dan tidak serupa dengan data pada cluster lain[2].

Beberapa tahap dari algoritma K-Means dapat dilihat pada algoritma berikut :

1. Penentuan Awal cluster

Dalam menentukan $\mathrm{n}$ buah pusat cluster awal dilakukan pembangkitan bilangan random yang merepresentasikan urutan data input. Pusat awal cluster didapatkan dari data sendiri bukan dengan menentukan titik baru, yaitu dengan random pusat awal dari data.

2. Perhitungan jarak dengan pusat cluster

Untuk mengukur jarak antar data dengan pusat dengan cluster digunakaneuclidian distance, algoritma perhitungan jarak data dengan pusat cluster :

a. Pilih nilai data dan nilai pusat cluster

b. Hitung euclidian distance data dengan tiap pusat cluster

$$
\left(X \_i, \mu \_j\right)=\sqrt{ }\left(\left(X \_i-\mu \_j\right)\right)^{2}
$$

Penjelasan :

$$
\begin{aligned}
& X \_i \text { : Data kriteria } \\
& \mu \_i \text { : Centroid pada cluster ke j. }
\end{aligned}
$$

\section{Pengelompokan Data}

Jarak hasil perhitungan akan dilakukan perbandingan dan dipilih jarak terdekat antara data dengan pusat cluster, jarak ini menunjukan bahwa data tersebut berada dalam satu kelompok dengan pusat cluster terdekat. Adapun cara pengelompokan data tersebut adalah :

a.Pilih nilai jarak tiap pusat cluster dengan data.

b. Cari nilai jarak terkecil.

c. Kelompokkan data dengan pusat cluster yang memiliki jarak terkecil.

4. Penentuan Pusat Cluster baru

Untuk mendapatkan pusat cluster baru bisa dihitung dari rata-rata nilai anggota cluster dan pusat cluster. Pusat cluster yang baru digunakan untuk melakukan iterasi selanjutnya, jika hasil yang didapatkan belum konvergen. Proses iterasi akan berhenti jika telah memenuhi maksimum iterasi yang dimasukkan oleh user atau hasil yang dicapai sudah konvergen (pusat cluster baru sama dengan pusat cluster lama).

5. Algoritma Penentuan pusat cluster :

a. Cari jumlah anggota tiap cluster

b. Hitung pusat baru dengan rumus $\mu \mathrm{j}(t+1)=1 / \mathrm{Nsj} \sum \mathrm{j} \epsilon \mathrm{S}_{-} \mathrm{j} X_{-} \mathrm{j}$

Penjelasan : 
$\mu \_\mathrm{j}(\mathrm{t}+1)$ : Centroid baru pada iterasi ke 1

$\mathrm{Nsj}$ : Banyak data pada cluster $\mathrm{S} \_j_{j}$

\subsection{DBI (Davies Bouldin Index)}

Davies bouldin index (DBI) adalah metric untuk mengevaluasi atau mempertimbangkan hasil algoritma clustering. Pertama kali diperkenalkan oleh David L. Davies dan Donald W. Bouldin pada tahun 1979. Dengan menggunakan DBI suatu cluster akan dianggap memiliki skema clustering yang optimal adalah yang memiliki DBI minimal.

Langkah-langkah perhitungan Davies Bouldin Index adalah Sebagai berikut :

\section{Sum Of Square Within-Cluster(SSW)}

Untuk mengetahui kohesi dalam sebuh cluster ke-I salah satunya adalah dengan menghitung nilai dari Sum Of Square Within-Cluster (SSW). Dengan rumus sebagai berikut :

$$
S S W_{i}=\frac{1}{m i} \sum_{j=i}^{m i} d\left(X_{j}, C_{j}\right)
$$

Dimana :

$$
\begin{array}{ll}
m i \quad= & \text { jumlah data dalam cluster } \mathrm{ke}-\mathrm{i} \\
c i & =\text { centroid cluster } \mathrm{ke}-\mathrm{i}
\end{array}
$$

\section{Sum Of Square Between-Cluster (SSB)}

Perhitungan Sum Of Square Between-Cluster (SSB) bertujuan untuk mengetahui separasi atau jarak antar cluster. dengan rumus perhitungan sebagai berikut

Dimana :

$$
S S B_{i j}=d\left(X_{i}, X_{j}\right)
$$

$d\left(X_{i}, X_{j}\right)=$ jarak antara data ke $i$ dengan data ke $j$ di cluster lain.

\section{Ratio (Rasio)}

Perhitungan rasio $(\mathrm{Ri}, \mathrm{j})$ ini bertujuan untuk mengetahui nilai perbandingan antara cluster ke-i dan cluster ke-j untuk menghitung nilai rasio yang dimiliki oleh masing-masing cluster. indeks $\mathrm{I}$ dan $\mathrm{j}$ merupakan merepresentasikan jumlah cluster, dimana jika terdapat 4 cluster maka terdapat indeks sebanyak 4 yaitu i,j,k dan 1 . untuk menentukan nilai rasio dengan rumus sebagai berikut :

$$
R_{i j \ldots \ldots, n}=\frac{S S W_{i}+S S W_{j}+\cdots+S S W_{n}}{S S B_{i, j}+\cdots+S S B_{n i, n j}}
$$

Dimana :

$S S W_{i}=$ Sum Of Square Within-Cluster pada centroid $i$

$S S B_{i, j}=$ Sum of Square Between Cluster data ke $i$ dengan $j$ pada cluster yang berbeda

Pada rumus perhitungan $2.5 n$ akan berlanjut sejumlah cluster yang dipilih dengan syarat $n i$ tidak sama dengan $n j$.

4. Davies Bouldin Index (DBI)

Nilai rasio yang diperoleh dari rumus 2.5 digunakan untuk mencari nilai DBI dengan menggunakan perhitungan sebagai berikut :

$$
D B I=\frac{1}{k} \sum_{i=1}^{k} \max _{i \neq j}(R i, j, \ldots k)
$$

Dimana, Ri,j merupakan ratio dari nilai SSW dan SSB melalui perhitungan rumus 2.5 dari perhitungan 2.6 maka dapat diketahui k adalah jumlah cluster. Dari perhitungan Davies Bouldin Index (DBI) dapat disimpulkan bahwa jika semakin kecil nilai Davies Bouldin Index (DBI) yang diperoleh (non negatif >=0) maka cluster tersebut semakin baik. 


\section{Metode Penelitian}

Penelitian ini akan melalui beberapa proses, alur urutan proses pada penelitian ini adapat dilihat sebagai mana pada gambar berikut :

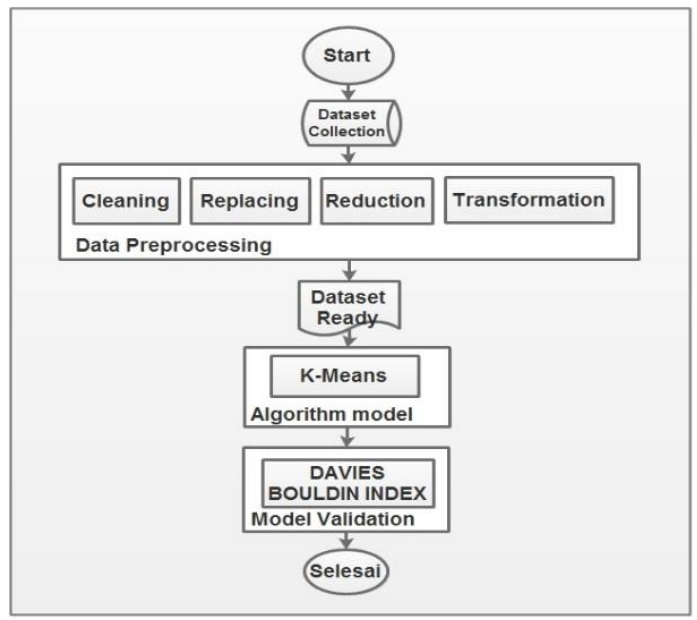

Gambar 1. Metode Penelitian

Tahapan awal dalam penelitian ini adalah dimulai dengan memilih dataset yang akan digunakan, pada awal penelitian dataset yang digunakan ialah data nilai siswa dan siswi di SMK Binamitra Cikarang Timur. Pengumpulan data ini dilakukan pada nilai dari Nilai Penilaian Tengah Semester (PTS). Pengumpulan data berdasarkan data yang dibutuhkan pada penelitian ini diharapkan dapat memperoleh data-data yang relevan, akurat dan terpercaya.

Pengumpulan data ini dilakukan melalui pengambilan data dari siswa kelas 10, 11, dan 12 semua jurusan untuk mata pelajaran Matematika di SMK Binamitra yang selanjutnya di olah menggunakan algoritma $k$ means. Data yang akan di pakai adalah data nilai siswa dan siswi kelas 10, 11, dan 12 yang telah diberikan oleh pihak sekolah SMK Binamitra.

Pada Penelitian ini evaluasi yang digunakan untuk mengetahui hasil akurasi dari algoritma k-means dan mengelompokan minat siswa terhadap mata pelajaran matematika. Validasi bertujuan untuk melihat perbandingan hasil dari model atau metode yang digunakan dengan hasil yang telah ada sebelumnya. Teknik validasi yang digunakan dalam penelitian ini adalah Performance Vector, akurasi algoritma akan diukur menggunakan Davies Bouldin Index.

\section{Hasil dan Pembahasan}

Pada penelitian ini jumlah data set yang digunakan sebanyak 334 data kelas 10, 11 dan 12 dari semua jurusan di SMK Binamitra, dan perhitungan akan di ambil dari kelas 10 dari 108 siswa saja untuk contoh. 


\begin{tabular}{|c|c|c|c|c|c|}
\hline No & Nama & Kelas 10 (Jurusan) & $\begin{array}{l}\text { RT2 NILAI } \\
\text { ULNGN HRN }\end{array}$ & $\begin{array}{c}\text { NILAI ASLI } \\
\text { PTS }\end{array}$ & $\begin{array}{c}\text { NILAI AKHIR } \\
\text { PTS }\end{array}$ \\
\hline 1 & Ach Syauqi Al-Hakim & TKR & 7 & 1 & 6 \\
\hline 2 & Ade Indra Febrian & TKR & 5 & 1 & 5 \\
\hline 3 & Ade Priana & TKR & 7 & 2 & 7 \\
\hline 4 & Agil Setiawan & TKR & 7 & 1 & 6 \\
\hline 5 & Ananta Surya Jaya & TKR & 7 & 2 & 7 \\
\hline 6 & Antoni Diyan Anugra & TKR & 7 & 1 & 5 \\
\hline 7 & Arya Bagus Susanto & TKR & 7 & 2 & 7 \\
\hline 8 & Didan Surul Mulyadi & TKR & 7 & 1 & 6 \\
\hline 9 & Dimas Adhitia & TKR & 5 & 1 & 5 \\
\hline 10 & Erwin & TKR & 7 & 2 & 7 \\
\hline$\ldots$ & $\ldots$ & $\ldots$ &.. & $\ldots$ & $\ldots$ \\
\hline 40 & Intan Sopiyanti & AKUTANSI & 8 & 5 & 8 \\
\hline 41 & Keywa Guardian & AKUTANSI & 7 & 4 & 6 \\
\hline 42 & Kurtubi Ziafahrezi & AKUTANSI & 7 & 2 & 5 \\
\hline 43 & Mia Aditya & AKUTANSI & 8 & 4 & 7 \\
\hline 79 & Aldi Junaedi & TKJ & 2 & 3 & 2 \\
\hline 80 & Syahfitri Azzahra & TKJ & 6 & 7 & 6 \\
\hline 106 & Fitria Anggrayani & TKJ & 6 & 7 & 6 \\
\hline 107 & Putri Wulandari & $\mathrm{TKJ}$ & 6 & 7 & 7 \\
\hline 108 & Cahyo Agil Pratama & TKJ & 3 & 2 & 4 \\
\hline
\end{tabular}

Tabel 1 Contoh Data Siswa Kelas 10

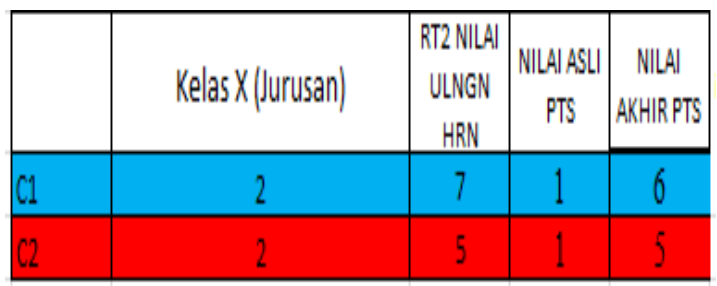

Tabel 2 Contoh Centroid awal kelas 10

1. Hitung jarak data dengan centroid Eucliden Distance dengan rumus sebagai berikut :

$$
\left(X_{i}, \mu_{j}\right)=\sqrt{\left(X_{i}-\mu_{j}\right)^{2}}
$$

a. C1 ( data 1, Centroid 1)

$$
\begin{aligned}
& =\sqrt{\left.(2-2)^{2}+(7-7)^{2}+(1-1)^{2}+(6-6)^{2}\right)} \\
& =\mathbf{0}
\end{aligned}
$$

b. C2 (data 1, centroid 2)

$$
\begin{aligned}
& =\sqrt{\left.(2-2)^{2}+(7-5)^{2}+(1-1)^{2}+(6-5)^{2}\right)} \\
& =\mathbf{2 . 2 3 6 0 6 8}
\end{aligned}
$$

\section{$=2.236068$}




\begin{tabular}{|r|r|r|r|}
\hline No & \multicolumn{1}{|c|}{ C1 } & \multicolumn{1}{c|}{ C2 } & $\begin{array}{c}\text { JARAK } \\
\text { MINIMAL }\end{array}$ \\
\hline 1 & 0 & 2,236068 & 0 \\
\hline 2 & 2,236068 & 0 & 0 \\
\hline 3 & 1,414214 & 3 & 1,414214 \\
\hline 4 & 0 & 2,236068 & 0 \\
\hline 5 & 1,414214 & 3 & 1,414214 \\
\hline 6 & 1 & 2 & 1 \\
\hline & $\ldots$ & $\ldots$ & $\ldots$ \\
\hline & 5,477226 & 3,605551 & 3,605551 \\
\hline 104 & 6,082763 & 4,242641 & 4,242641 \\
\hline 105 & 6,480741 & 6,403124 & 6,403124 \\
\hline 106 & 6,164414 & 6,244998 & 6,164414 \\
\hline 107 & 6,244998 & 6,480741 & 6,244998 \\
\hline 108 & 4,690416 & 2,645751 & 2,645751 \\
\hline
\end{tabular}

Tabel 3 contoh Hasil Perhitungan Jarak Pusat Cluster kelas 10

Untuk centroid baru didapatkan dari jumlah seluruh data sebuah atribut pada satu centroid dibagi dengan jumlah data dan berlaku untuk seterusnya untuk semua atribut centroid. Sebagai contoh untuk atribut umur pada centroid pertama. Proses kembali lagi ke langkah 2 yaitu dengan menggunakan centroid baru dari iterasi pertama yang dihitung dari nilai rata-rata tiap kelompok cluster. Untuk centroid baru didapatkan dari jumlah seluruh data sebuah atribut pada satu centroid dibagi dengan jumlah data dan berlaku untuk seterusnya untuk semua atribut centroid. Sebagai contoh untuk atribut Jurusan pada kelas 10 pada centroid pertama :

\section{jumlah seluruh jurusan pada kelas 10 cluster pertama banyak data pada cluster pertama}

$$
\frac{158}{73}=2,164
$$

\begin{tabular}{|c|c|c|c|c|c|}
\hline \multirow{3}{*}{ C1 } & No & $\begin{array}{c}\text { Kelas X } \\
\text { (Jurusan) }\end{array}$ & $\begin{array}{c}\text { RT2 NILAI } \\
\text { ULNGN } \\
\text { HRN }\end{array}$ & $\begin{array}{c}\text { NILAI ASLI } \\
\text { PTS }\end{array}$ & $\begin{array}{c}\text { NILAI } \\
\text { AKHIR PTS }\end{array}$ \\
\hline 1 & 2 & 7 & 1 & 6 \\
\hline 2 & 2 & 7 & 2 & 7 \\
\hline 3 & 2 & 7 & 1 & 6 \\
\hline 4 & 2 & 7 & 2 & 7 \\
\hline 5 & 2 & 7 & 1 & 5 \\
\hline 6 & 2 & 7 & 2 & 7 \\
\hline 7 & 2 & 7 & 1 & 6 \\
\hline 8 & 2 & 7 & 2 & 7 \\
\hline 9 & 2 & 7 & 1 & 6 \\
\hline 10 & 2 & 7 & 1 & 7 \\
\hline$\ldots$. & $\ldots$ & $\ldots$ & $\ldots .$. & $\ldots$ \\
\hline 71 & 1 & 6 & 7 & 6 \\
\hline 72 & 1 & 6 & 7 & 7 \\
\hline 73 & 1 & 3 & 2 & 4 \\
\hline
\end{tabular}

Tabel 4 Data Cluster Pertama Kelas 10

Dimana perhitungan pengulangan pada penelitian ini dengan centroid baru berhenti pada perhitungan iterasi 
P-ISSN 2620-8342

E-ISSN 2621-3052

ke 2. Dimana centroid terakhir yang tidak mengalami perubahan.

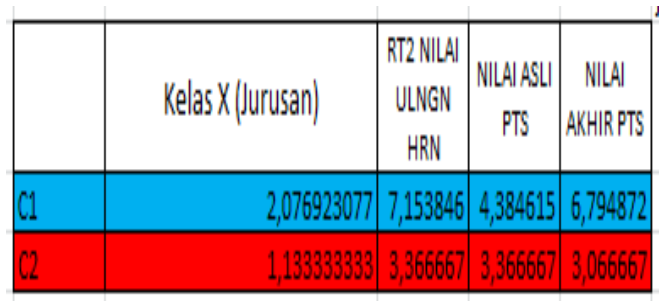

Tabel 1 Centroid Terakhir kelas 10

\begin{tabular}{|c|c|c|c|c|c|c|c|c|}
\hline № & Nama & $\begin{array}{c}\text { Kelas I0 } \\
\text { (Jurusan } \\
1\end{array}$ & \begin{tabular}{|c|} 
RT2 NILAA \\
ULNGN \\
HRN \\
\end{tabular} & $\begin{array}{c}\text { NILA ASU } \\
\text { PTS }\end{array}$ & $\begin{array}{c}\text { NILAI } \\
\text { AKHIR PTS }\end{array}$ & $\mathrm{Cl}$ & $\mathrm{C} 2$ & \begin{tabular}{|c|} 
JARAK \\
MINIMAL \\
\end{tabular} \\
\hline & 1 |Ach Syauqi Al-Hakim & 2 & 7 & 1 & 6 & 3,471448 & 5,418692 & 3,471448 \\
\hline & 2 Ade Indra Febrian & 2 & 5 & 1 & 5 & 4,411486 & 3,664545 & 3,664545 \\
\hline & 3)Ade Priana & 2 & 7 & 2 & 7 & 2,391155 & 5,694637 & 2,391155 \\
\hline & \begin{tabular}{l|l|}
4 & Agil Setiawan \\
\end{tabular} & 2 & 7 & 1 & 6 & 3,471448 & 5,418692 & 3,471448 \\
\hline & 5 Ananta Surya Jaya & 2 & 7 & 2 & 7 & 2,391155 & 5,694637 & 2,391155 \\
\hline & 6 Antoni Diyan Anugrah & 2 & 7 & 1 & 5 & 3,826316 & 4,949298 & 3,826316 \\
\hline & 7 Arya Bagus Susanto & 2 & 7 & 2 & 7 & 2,391155 & 5,694637 & 2,391155 \\
\hline & 8 Didan Surul Mulyadi & 2 & 7 & 1 & 6 & 3,471448 & 5,418692 & 3,471448 \\
\hline & 9 Dimas Adhitia & 2 & 5 & 1 & 5 & 4,411486 & 3,664545 & 3,664545 \\
\hline & \begin{tabular}{l|l|}
10 & Erwin \\
\end{tabular} & 2 & 7 & 2 & 7 & 2,391155 & 5,694637 & 2,391155 \\
\hline & 11 Farhan Rahmansyah & 2 & 7 & 1 & 6 & 3,471448 & 5,418692 & 3,471448 \\
\hline & 12 Hendi Hadiwijaya & 2 & 7 & 1 & 7 & 3,385441 & 6,019044 & 3,385441 \\
\hline & 13 Herdi Eka Prasetya & 2 & 7 & 1 & 7 & 3,385441 & 6,019044 & 3,385441 \\
\hline & 14 Herfila Ikhsan Ade Putr. & 2 & 7 & 1 & 6 & 3,471448 & 5,418692 & 3,471448 \\
\hline$\ldots$ & \begin{tabular}{|c|}
$\ldots$ \\
\end{tabular} & $\ldots$ & $\ldots$ & $\ldots$ & $\ldots$ & $\ldots$ & $\ldots$ & \begin{tabular}{|c|}
$\ldots .$. \\
\end{tabular} \\
\hline & 05 Adelia Cahyati & 1 & 5 & 7 & 7 & 3,605506 & 5,618027 & 3,605506 \\
\hline & 06 Fitria Anggrayani & 1 & 6 & 7 & 6 & 3,190479 & 5,406375 & 3,190479 \\
\hline & 07 Putri Wulandari & 1 & 6 & 7 & 7 & 3,096678 & 6,007958 & 3,096678 \\
\hline & 08 [Cahyo Agil Pratama & 1 & 3 & 2 & 4 & 5,683957 & 1.7016: & 1,701633 \\
\hline
\end{tabular}

Tabel 2 Hasil Iterasi Terakhir kelas 10

2. Evaluasi Davies Bouldin Index (DBI)

$$
\begin{gathered}
S S W_{1}=\frac{\begin{array}{c}
3.471+2.326+2.391+3.471+2.391+ \\
78
\end{array}}{=\frac{403.4772}{78}} \\
=\mathbf{5 . 1 7 2 7 8} \\
S S W_{2}=\frac{\begin{array}{l}
3.666+3.664 .096+3.6444+4.650+ \\
1.869+\cdots \ldots+167+1.701
\end{array}}{30} \\
=\frac{403.4772}{30}
\end{gathered}
$$$$
=18.39951
$$

Setelah megetahui nilai SSW maka selanjutnya dilakukan perhitungan Sum of square between-cluster (SSB). Untuk menghitung nilai SSB maka diperlukan centroid terakhir pada iterasi terakhir pada perhitungan SSB dilakukan sebagai berikut:

$$
S S B_{1,2}
$$




$$
\mathbf{5 . 4 9 2}
$$

Setelah nilai SSW dan nilai SSB telah dihitung dan mendapatkan hasilnya, maka selanjutnya adalah mencari nilai rasio antar cluster dengan perhitungan sebagai berikut :

$R_{1}=\frac{s s w}{s s b}$

$R_{1}=\frac{5.17278}{5.492}=\mathbf{0 . 9 4 1}$

$R_{2}=\frac{s s w}{s s b}$

$R_{2}=\frac{1.839951}{5.492}=\mathbf{0 . 3 3 5}$

Setelah mengetahui rasio antar cluster kemudian hitunglah nilai DBI sebagai berikut :

$$
\begin{aligned}
\mathrm{DBI}= & \frac{R_{1}+R_{2}}{K} \text { atau } \frac{R_{1}+R_{2}}{2} \\
= & \frac{0.941+0.335}{2} \\
& =\mathbf{0 . 6 3 8}
\end{aligned}
$$

Setelah melakukan pengklasteran data dan melakukan pengujian menggunakan sistem $k$-means maka dapat disimpulkan bahwa Kelas 10 dari 2 cluster yaitu C1 ( Minat Matematika) dengan jumlah siswa 78 siswa, cluster C2 ( Tidak Minat Matematika ) dengan jumlah siswa 30, dapat dilihat jumlah siswa kelas 10 minat terhadap mata pelajaran matematika lebih banyak dibandingkan kurang minat. Berdasarkan hasil analisa persentase dari, 2 cluster didapatkan hasil $82 \%$ yang minat dan $18 \%$ utntuk siswa yang kurang minat.

\begin{tabular}{|l|c|c|l|}
\hline $\begin{array}{l}\text { Cluster 1 } \\
(\text { C1) }\end{array}$ & 78 & $80 \%$ & $\begin{array}{l}\text { Minat } \\
\text { Matematika }\end{array}$ \\
\hline $\begin{array}{l}\text { Cluster 2 } \\
\text { (C2) }\end{array}$ & 30 & $20 \%$ & Kurang Minat \\
\hline Total & 108 & $100 \%$ & \\
\hline
\end{tabular}

Tabel 7 Hasil Clustering Kelas 10

Evaluasi hasil dari Davies bouldin index ( DBI ) dari tiap kelas dan mendapatkan hasil nilai sebagai berikut

\begin{tabular}{|c|c|c|c|}
\hline KELAS & R1(C1) & $\begin{array}{c}\text { R2 } \\
(\mathrm{C} 2)\end{array}$ & DBI \\
\hline 10 & 0.941 & 0.335 & 0.638 \\
\hline 11 & 0.660 & 0.506 & 0.583 \\
\hline 12 & 0.271 & 0.111 & 0.191 \\
\hline
\end{tabular}

Tabel 8 Hasil Clustering Kelas 10

Evaluasi hasil dari Davies Bouldin Index mendekati angka 0 mengartikan bahwa masing-masing anggota 
yang ada didalam cluster berada dalam jarak yang berdekatan. Semakin kecil nilai davies bouldin index maka semakin baik cluster yang diperoleh dari pengelompokan menggunakan metode clustering.

Hasil perhitungan dari kelas 10 menggunakan algoritma k-means menunjukan nilai 0.638 angka tersebut memiliki hasil yang cukup baik karena mendekati angka 0. Dari perhitungan Davies Bouldin Index (DBI) dapat disimpulkan bahwa jika semakin kecil nilai Davies Bouldin Index (DBI) yang diperoleh (non negatif $>=0$ ) maka cluster tersebut semakin baik.

\section{Kesimpulan}

Dari hasil penelitian yang telah dilakukan oleh peneliti, maka dapat diperoleh kesimpulan sebagai berikut

1) Berdasarkan data yang telah diperoleh untuk membantu pengelompokan siswa dan siswi, untuk pengelompokan minat atau tidak minat dalam mata pelajaran matematika menggunakan metode K-Means dapat diimplementasikan di SMK Binamitra.

2) Dari Data kelas 10 dengan 2 Cluster di dapatkan hasil cluster 1 yaitu ( Minat ) Dengan Total Jumlah 78 data siswa, cluster 2 yaitu ( Tidak Minat ) Dengan Total Jumlah 30 data siswa, dengan jumlah siswa 108 siswa. Penguji menggunakan validasi DBI ( Davies Bouldin Index) diperoleh nilai untuk tiap-tiap cluster. pengujian cluster 1( Minat ) menghasilkan nilai DBI 0.941, cluster 2 menghasilkan nilai DBI 0.335. Karena nilai DBI dari cluster 2 lebih kecil maka cluster tersebut bisa disebut optimal.

3) Data kelas 11 dengan 2 Cluster di dapatkan hasil cluster 1 yaitu ( Minat ) Dengan Total Jumlah 86 data siswa, cluster 2 yaitu ( Tidak Minat ) Dengan Total Jumlah 20 data siswa. Dengan jumlah siswa 106 siswa. Penguji menggunakan validasi DBI ( Davies Bouldin Index) diperoleh nilai untuk tiap-tiap cluster. pengujian cluster 1( Minat ) menghasilkan nilai DBI 0.660, cluster 2 menghasilkan nilai DBI 0.506. Karena nilai DBI dari cluster 2 lebih kecil maka cluster tersebut bisa disebut optimal.

4) Data kelas 12 dengan 2 Cluster di dapatkan hasil cluster 1 yaitu ( Minat ) Dengan Total Jumlah 42 data siswa, cluster 2 yaitu ( Tidak Minat ) Dengan Total Jumlah 78 data siswa. Dengan jumlah siswa 120 siswa. Penguji menggunakan validasi DBI ( Davies Bouldin Index) diperoleh nilai untuk tiap-tiap cluster. pengujian cluster 1( Minat ) menghasilkan nilai DBI 0.271, cluster 2 menghasilkan nilai DBI 0.111. Karena nilai DBI dari cluster 2 lebih kecil maka cluster tersebut bisa disebut optimal.

Penelitian selanjutnya dapat dikembangkan dengan data yang serupa dengan metode yang sama dengan melakukan kombinasi atau pendekatan yang lain guna mendapatkan hasil penelitian yang lebih baik.

\section{Daftar Pustaka}

[1] L. Landau, "Hakikat Matematika," Zhurnal Eksp. i Teor. Fiz., pp. 12-65, 1937.

[2] N. Narwati, "Pengelompokan Mahasiswa Menggunakan Algoritma K-Means," J. Din. Inform., vol. 2, no. 2, 2010.

[3] F. Nasari and S. Darma, "Seminar Nasional Teknologi Informasi dan Multimedia 2015 Penerapan KMeans Clustering Pada Data Penerimaan Mahasiswa Baru (Studi Kasus : Universitas Potensi Utama)," pp. 6-8, 2015.

[4] F. E. M. Agustin, "Implementasi Algoritma K-Means Untuk Menentukan Kelompok Pengayaan Materi Mata Pelajaran Ujian Nasional (Studi Kasus: Smp Negeri 101 Jakarta),” J. Tek. Inform., vol. 8, no. 1, pp. 73-78, 2015.

[5] M. R. L. Iin Parlina, Agus Perdana Windarto, Anjar Wanto, "Memanfaatkan Algoritma K-Means Dalam Menentukan Pegawai Yang Layak Mengikuti Asessment Center,” vol. 3, no. 1, pp. 87-93, 2018.

[6] R. A. Djamro, "Penerapan Algoritma K-Means Dalam Memilih Tanah Yang Tepat Untuk Tanaman Padi," vol. VII, no. 1, pp. 12-20, 2018.

[7] A. Bastian et al., "Penerapan Algoritma," Jsi.Cs.Ui.Ac.Id, vol. 14, no. 1, pp. 26-32, 2009.

[8] Y. Siyamto, "Pemanfaatan Data Mining Dengan Metode Clustering Untuk Evaluasi Biaya Dokumen Ekspor Di Pt Winstar Batam," Media Inform. Budidarma, vol. 1, no. 2, pp. 28-31, 2017.

[9] S. Haryati, A. Sudarsono, and E. Suryana, "Implementasi Data Mining Untuk Memprediksi Masa Studi Mahasiswa Menggunakan Algoritma C4.5 (Studi Kasus: Universitas Dehasen Bengkulu),” J. Media Infotama, vol. 11, no. 2, pp. 130-138

[10] B. J. Dehotman, "Peningkatan Hasil Evaluasi Clustering Davies-Bouldin Index dengan Penentuan Titik Pusat Cluster Awal Algoritma K-Means,” 2018. 